\title{
Influence of glyphosate herbicide treatment of couch grass on take-all caused by Gaeumannomyces graminis var. tritici with the addition of soil-borne microorganisms
}

\author{
R.F. van Toor, S.F. Chng, R.M. Warren and R.C. Butler \\ The New Zealand Institute for Plant \& Food Research Limited, Private Bag 4704, \\ Christchurch 8140, New Zealand \\ Corresponding author: Ronald.vanToor@plantandfood.co.nz
}

\begin{abstract}
Couch grass rhizomes harbour Gaeumannomyces graminis var. tritici (Ggt), which causes take-all of wheat. Glyphosate used after cereal harvest to control couch can increase takeall in subsequent wheat crops. Following glyphosate treatment, the colonisation of senescing couch rhizomes by Ggt when treated with the endophytic fungus Microdochium bolleyi, and the spread of Ggt from senescing couch rhizomes to wheat when treated with the rhizobacterium Pseudomonas fluorescens, were investigated in two separate experiments. In Experiment 1, glyphosate increased Ggt inoculum in couch, irrespective of whether M. bolleyi was added to the potting medium. In Experiment 2, take-all severity and Ggt DNA concentration in roots of the accompanying wheat plants tended to decrease with glyphosate treatment of couch and increase only when P. fluorescens was added. Soil-borne microflora in fields containing glyphosate-sprayed couch may affect expression of take-all in subsequent wheat.
\end{abstract}

Keywords soil-borne disease, take-all, glyphosate, inoculum suppression, Microdochium bolleyi, Pseudomonas fluorescens.

\section{INTRODUCTION}

Take-all, caused by the fungus Gaeumannomyces graminis var. tritici $(G g t)$, is the most important root disease of wheat (Triticum aestivum) worldwide (Hornby et al. 1998a), resulting in blackened roots, stunting and premature death of affected plants. Between crops, Ggt survives saprophytically on infected host residues, and inoculum concentrations decline as the residue decays (Hornby 1981). The amount of inoculum present in the soil when the crop is seeded affects the extent of primary infection of a susceptible host cereal such as wheat (Bailey \& Gilligan
1999). Ggt-infected grass weeds can also be a source of inoculum (Gutteridge et al. 2005), particularly the rhizomatous grass weed couch (Elytrigia repens) (Chng et al. 2004).

The herbicide glyphosate is often used to manage couch and other grass weeds between crops, usually within 1-3 months after harvest (RA Craigie, New Zealand Foundation for Arable Research, pers. comm.). However, this practice often can lead to increased Ggt inoculum in soil within 2 months of glyphosate application if the couch or grass weeds were already infected with 
Ggt (Bithell et al. 2009). Ggt can transmit from dying/senescing plants to the subsequent crop (Hornby et al. 1998b).

Glyphosate can increase the conduciveness of the soil to take-all of wheat by selectively suppressing the activity of microorganisms antagonistic to Ggt (Mekwatanakarn \& Sivasithamparam 1987). In surviving plants, glyphosate inhibits the enzymatic activity in the shikimate pathway (Steinrucken \& Amrhein 1980), preventing formation of phenolic compounds associated with plant defences (Hammerschmidt 1999) and making surviving plants such as couch more susceptible to Ggt colonisation. Some microorganisms are common on roots infected with Ggt and in the root rhizosphere. In New Zealand, the endophytic fungus Microdochium bolleyi co-occurs with Ggt regularly (Chng et al. 2004) and is known overseas to potentially reduce take-all severity (Kirk \& Deacon 1987). Pseudomonas fluorescens is also found regularly on wheat roots (Chng et al. 2015) in New Zealand, and reported to antagonise Ggt and limit infection in fields grown with continuous wheat crops overseas (Kwak \& Weller 2013). However, it is not known if these microorganisms influence take-all severity in wheat sown after application of glyphosate to weeds.

In this study, the effects of applying glyphosate to couch grown with these microorganisms on colonisation of Ggt in couch or its spread to wheat were investigated in two separate greenhouse pot experiments. The influence of Microdochium bolleyi on further colonisation of couch rhizomes by Ggt following glyphosate application of couch was assessed in Experiment 1. The influence of P. fluorescens on transmission of Ggt from Ggt-infected couch plants treated with glyphosate to newly sown wheat plants was assessed in Experiment 2.

\section{MATERIALS AND METHODS \\ Materials used in both experiments}

Steam-sterilised river sand was used as the potting medium to facilitate root harvest at the end of the experiment. Muslin cloth was placed at the base of each pot to prevent sand loss. Each pot also contained fertiliser at concentrations per $\mathrm{kg}$ of sand: $2.4 \mathrm{~g}$ dolomite lime, $2.4 \mathrm{~g}$ Osmocote $^{\mathrm{TM}}$ 15-9-12, $1.0 \mathrm{~g}$ garden lime, $0.8 \mathrm{~g}$ super phosphate, $0.3 \mathrm{~g}$ calcium nitrate, $0.3 \mathrm{~g}$ sulphate of potash and $1.1 \mathrm{~g}$ zeolite.

The Ggt inoculum was composed of oat grains infected with pathogenic Ggt isolates H9T3 R1/1.2, Biomill SC3, A3SL4, 1201/w-1 and H11T3 R1/3 (Chng et al. 2005) from the Plant \& Food Research Lincoln culture collection.

The experiments were conducted in a greenhouse set at $18^{\circ} \mathrm{C}$, with the pots positioned $25 \mathrm{~cm}$ to $30 \mathrm{~cm}$ apart from one another. The pots were laid out in a Latinised row by column design (generated using CycDesign 5.1 (VSN International Ltd 2013)) in a greenhouse maintained at $18^{\circ} \mathrm{C}$ with $12 \mathrm{~h}$ light/dark photoperiods. The pots were watered daily with tap water to near saturation without run-off.

\section{Experiment 1}

The experiment was designed to determine the effect of M. bolleyi on Ggt colonisation of couch before and after glyphosate treatment. The treatments comprised combinations of Ggt $( \pm G g t)$, Herbicide $( \pm$ glyphosate 4 weeks after planting couch rhizomes) and Microdochium ( \pm M. bolleyi added at 2 or 8 weeks after planting). In addition, for each Ggt, glyphosate and $M$. bolleyi combination, there were up to five pots per replicate, with the plants in these being destructively harvested 2, 4, 8, 12 or 16 weeks after planting (Table 1), depending on the timing of the glyphosate and M. bolleyi treatments. The 27 treatment-harvest combinations were replicated four times, giving 108 pots in total. 
Table 1 Treatment details of pot Experiment 1.

\begin{tabular}{lccccc}
\hline $\begin{array}{l}\text { Treatment } \\
\text { no. }\end{array}$ & $\begin{array}{c}\text { Ggt added at } \\
\text { week 0 }\end{array}$ & $\begin{array}{c}\text { Glyphosate at } \\
\text { week 4 }\end{array}$ & $\begin{array}{c}\text { Microdochium } \\
\text { bolleyi }\end{array}$ & Harvests & Harvest week $^{*}$ \\
\hline $1-5$ & - & - & - & 5 & $2,4,8,12,16$ \\
$6-8$ & - & + & - & 3 & $8,12,16$ \\
$9-13$ & + & - & - & 5 & $2,4,8,12,16$ \\
$14-16$ & + & + & - & 3 & $8,12,16$ \\
$17-20$ & + & - & + at week 2 & 4 & $4,8,12,16$ \\
$21-23$ & + & + & + at week 2 & 3 & $8,12,16$ \\
$24-25$ & + & - & + at week 8 & 2 & 12,16 \\
$26-27$ & + & + & + at week 8 & 2 & 12,16 \\
\hline
\end{tabular}

${ }^{\star}$ Numbers of harvests were dependent on treatment times

Couch plants collected from a wheat field near Lincoln and maintained in potting mix were used in the experiment. In winter 2012, two healthy couch plants, each with at least one rhizome with three internodes, were transplanted into each rectangular pot $(160 \times 115 \times 60 \mathrm{~mm})$ containing $1160 \mathrm{~g}$ of autoclaved sand, slow-release fertiliser and $0.1 \%(\mathrm{w} / \mathrm{w})$ ground sterilized oat grains with or without Ggt M. bolleyi inoculum (isolate H2T3 R2/4, Plant \& Food Research Lincoln culture collection). This isolate was originally isolated from couch rhizomes from a wheat field in Canterbury and was prepared in potato dextrose (PD) broth as per Jadubansa et al. (1994). An $8 \% \mathrm{v} / \mathrm{v}(84 \mathrm{~mL})$ suspension of $M$. bolleyi at $1 \mathrm{x}$ $10^{4}$ spores $/ \mathrm{mL}$, or the same quantity of reverse osmosis (RO) water (none), was added to each designated pot to give an equivalent of $7.2 \times 10^{2}$ spores/g sand. The $M$. bolleyi suspension was applied 2 weeks after planting to allow Ggt to colonise the rhizomes and newly-formed couch roots before glyphosate application, or 8 weeks after planting and 4 weeks after glyphosate treatment when the herbicide-treated rhizomes had senesced. Four weeks after planting, Roundup Renew (360 g glyphosate/litre) was sprayed at 6 litre/ha to couch foliage of the designated pots using a knapsack boom sprayer.

\section{Experiment 2}

The experiment was designed to determine the influence of P. fluorescens on transfer of Ggt from infected couch following glyphosate treatment to wheat. Treatments were a factorial of Plant (wheat, couch), by Herbicide ( \pm glyphosate), Ggt (couch $\pm G g t$ ) combinations, each with and without Pseudomonas ( \pm P. fluorescens) (Table 2). The 18 treatments were replicated four times, giving 72 pots. Couch rhizomes (similar source from Experiment 1) were transferred into trays containing potting mix, and into trays containing potting mix and $1 \%$ Ggt inoculum (w/w). The trays were held in the greenhouse for a month. The derived Ggt-infected and non-infected couch plants were used in the experiment.

In January 2016, three rhizomes of Ggtinfected or three rhizomes of non-infected couch were added to the potting medium in their assigned pots $(100 \mathrm{~mm}$ diameter $\mathrm{x} 150 \mathrm{~cm}$ tall). Each pot contained $2651 \mathrm{~cm}^{3}$ of sand and fertiliser (equivalent to $3500 \mathrm{~g}$ ). The rhizomes, 50-80 mm long with two internodes, were buried $10 \mathrm{~mm}$ under the sand surface and in a triangle 50 $\mathrm{mm}$ around the centre. Pseudomonas fluorescens isolate PF1208-4 (Plant \& Food Research Lincoln bacteria culture collection) was used as the representative fluorescent pseudomonad. The isolate was obtained from the rhizosphere of wheat roots from a second-year wheat field in Canterbury. A single colony was inoculated into $1 \mathrm{~L}$ of modified King's B broth for 48 hours at $25^{\circ} \mathrm{C}$ with constant shaking. The mixture was 
centrifuged, the resulting pellet was washed with $\mathrm{RO}$ water and re-suspended in $0.1 \mathrm{M}$ magnesium sulphate, with the bacterial concentration adjusted to $6.7 \times 10^{4}$ colony forming units (CFU)/ $\mathrm{mL}$ of the sulphate solution.

When the developing shoots of the couch rhizomes were 10 to $20 \mathrm{~mm}$ long (12 days after planting), $100 \mathrm{~mL}$ of the Pseudomonas suspension was poured onto the surface centre of the pre-assigned pots, equivalent to $1.9 \times 10^{3}$ P. fluorescens PF1208-4 CFU/g sand.

Five weeks after planting (1 March), the approximately $200 \mathrm{~mm}$ long couch leaves from plants in the Herbicide-designated pots were treated with a $33 \%$ solution $(\mathrm{v} / \mathrm{v})$ of 'Watkins weed killer' (360 g glyphosate/litre). A paint brush was used to wipe the herbicide over the leaves while they were pressed against a tray. Wiping the couch foliage with the translocating herbicide instead of spraying, as in Experiment 2, prevented herbicide residues in the sand, which would have killed the wheat seedlings.

Three weeks after glyphosate application (18 March), four pre-germinated wheat seedlings (cv. 'Wakanui') with 50 to $100 \mathrm{~mm}$ long leaves (growth stage Zadoks 10) were planted to a depth of $25 \mathrm{~mm}$ at the cardinal points in a 30 to $40 \mathrm{~mm}$ radius around the centre of each wheatdesignated plot. The herbicide treated couch leaves had been trimmed the previous day to 50 $\mathrm{mm}$ above the crown, so as to limit the risk of the wheat seedlings coming into contact with the glyphosate-treated leaves. Five days later, each pot was supplemented with $100 \mathrm{~mL}$ of a nutrient fertiliser comprised of the following compounds (per litre): calcium nitrate $722 \mathrm{mg}$, potassium nitrate $253 \mathrm{mg}$, magnesium sulphate $246 \mathrm{mg}$, ammonium nitrate $40 \mathrm{mg}$, iron 20 $\mathrm{mg}$, potassium chloride $3.73 \mathrm{mg}$, potassium dihydrogen orthophosphate $23.1 \mathrm{mg}$, boric acid $1.420 \mathrm{mg}$, manganese sulphate $0.85 \mathrm{mg}$, zinc sulphate $0.115 \mathrm{mg}$, cupric sulphate $0.05 \mathrm{mg}$ and molybdic acid $0.016 \mathrm{mg}$.

All plants were harvested from each pot after 7 weeks of planting and processed for assessments.

\section{Assessments \\ Plants}

At each harvest plants were washed and rhizomes/roots severed from the foliage. Couch roots were removed from the rhizomes. In Experiment 1, the number of couch rhizomes having take-all lesions were assessed on a $0-6$ scale representing $0,10,30,50,70,85$ or $95 \%$ root infection, respectively, to derive a takeall index (\%) (Hornby \& Beale 2000) at each harvest. In Experiment 2, the washed roots of wheat plants per pot were assessed visually for the area of take-all (\% severity) that mimicked the take-all index percentage. The glyphosate treatment in Experiment 2 resulted in blackened couch rhizomes that masked take-all symptoms so comparisons of take-all for glyphosate treated and non-treated couch were not possible. For both experiments, the total couch rhizomes and wheat roots from each plot were airdried at $40^{\circ} \mathrm{C}$ for $72 \mathrm{~h}$, weighed and assesed for concentration of Ggt DNA.

\section{Ggt DNA quantification}

A representative subsample of dried couch rhizomes and all the dried wheat roots per pot were ground in liquid nitrogen in preparation for quantitative polymerase chain reaction ( $\mathrm{qPCR}$ ) assessments. DNA was extracted from a $\approx 20 \mathrm{mg}$ sub-sample of the ground tissue using a DNeasy Plant Minikit (Qiagen, New Zealand) following the manufacturer's instructions. The extracted DNA was suspended in $400 \mu \mathrm{L}$ (Experiment 1) or $200 \mu \mathrm{L}$ (Experiment 2) of TE manufacturer's buffer (pH 8.0).

The amount of Ggt DNA in each sample was quantified using the qPCR method described by Keenan et al. (2015). PCR amplifications were carried out in a StepOnePlus qPCR machine (Applied Biosciences) (Experiment 1), or a CFX96 Real-Time System (BioRad) (Experiment 2). A Sybr green-based qPCR with primers Pot25SF and Pot25SR confirmed all samples contained detectable plant DNA and thus no inhibitors likely to affect detection of Ggt DNA (Keenan et al. 2015). GgtProbe 1 and primers GgtEF1 and GgtEFR1 targeting the translation elongation 
factor 1-alpha (EF1-a) gene from Ggt measured the amount of Ggt DNA in the cereal roots. Standards of $0.01,0.1,1,10$ and $100 \mathrm{ng}$ Ggt DNA/ $\mu \mathrm{L}$, obtained from diluting Ggt DNA from extracts from pure Ggt culture, were included in the runs.

\section{Statistical analyses}

Initial analysis of spatial trends in the data across the pots showed the spatial effects were negligible and thus were not adjusted for. Couch rhizome and wheat root dry weights were analysed with analysis of variance, after first log-transforming to stabilise the variance. Take-all severity (\%) and wheat root dry weight as a percentage of total root dry matter (wheat plus couch) were analysed with a generalised linear model approach (McCullagh \& Nelder 1989) using a Poisson GLM with a logarithmic link for numbers, and binomial GLM with a logit link for the percentages.

For qPCR data, Ct values were first converted into quantities using parameters obtained from a standard linear regression value for the standards on the $\log _{10}$ concentration. Since the samples contained no inhibitors, the quantity was assumed to be 0 where the qPCR result was undetermined. The quantity of Ggt in each qPCR was then analysed using a Poisson-gamma hierarchical generalized linear model approach (HGLM) (Lee et al. 2006) with logarithmic links. Fixed effects were plant, couch, Ggt where applicable and Pseudomonas plus their interactions, fitted with a Poisson distribution. Individual pots were fitted as a random effect, with a gamma distribution. The analysis included an offset (McCullagh \& Nelder 1989) to adjust the results to be Ggt DNA concentrations per plant and per pot in appropriate units. The offset for per plant was

$$
\log n\left(\frac{q \text { PCRsampleWt }}{v o l \times D M}\right),
$$

where qPCRSampleWt is the weight $(\mathrm{mg})$ of the sample used for DNA extraction, DM is the dry weight of the roots or rhizomes and vol is the volume $(\mu \mathrm{L})$ the DNA was extracted into. The offset converts quantities on the required scale into the quantities actually measured.
All analyses were carried out with GenStat. For the ANOVA and GLM analyses, fixed effects, and contrasts of these were made using F-tests, or, for plant numbers since the data was not over-dispersed, $\chi^{2}$ tests. For the HGLM analyses, fixed effects were assessed using a $\chi^{2}$ test of the change in deviance on dropping the term, as implemented in Genstat's HGFTEST procedure (Payne et al. 2015).

Means and associated 95\% confidence limits (shown in brackets throughout) were obtained on the link or transformed scale, and backtransformed for presentation.

\section{RESULTS}

For both experiments, all couch plants that had been treated with glyphosate were dead after 3 weeks.

\section{Experiment 1}

Compared with non-herbicide treated plants, glyphosate increased take-all lesions on the senescing couch rhizomes by $20-40 \%(\mathrm{P}<0.001)$, and reduced rhizome dry weights by $100-200$ mg over time $(\mathrm{P}<0.001)$ (Figure 1$)$. In general, mean Ggt DNA concentrations in the senescing rhizomes increased by $10-15$ fold $(\mathrm{P}<0.001)$, irrespective of whether or not $M$. bolleyi was present. The background Ggt concentrations in rhizomes from couch plants grown in sand without added Ggtincreased by a similar amount. The addition of $M$. bolleyi either at week 2 or 8 had little effect on lesion development $(\mathrm{P}>0.065)$. Rhizomes had lower dry weights at the week- 8 assessment following the addition of M. bolleyi at week $2(\mathrm{P}<0.03)$ but not at the later assessments or from the addition at week 8 .

\section{Experiment 2}

Couch rhizome dry weight per plant was almost $20 \%$ lower $(\mathrm{P}=0.075)$ when planted with wheat than when planted alone (Table 2). Also, mean dry weight for rhizomes of couch treated with glyphosate ( $0.27 \mathrm{~g} /$ plant $)$ was substantially lower than for untreated couch $(10.5 \mathrm{~g} /$ plant; $\mathrm{P}<0.001)$. Inoculation with $G g t$ also reduced couch dry weight, by about $25 \%$ on average $(\mathrm{P}=0.009)$. Pots 

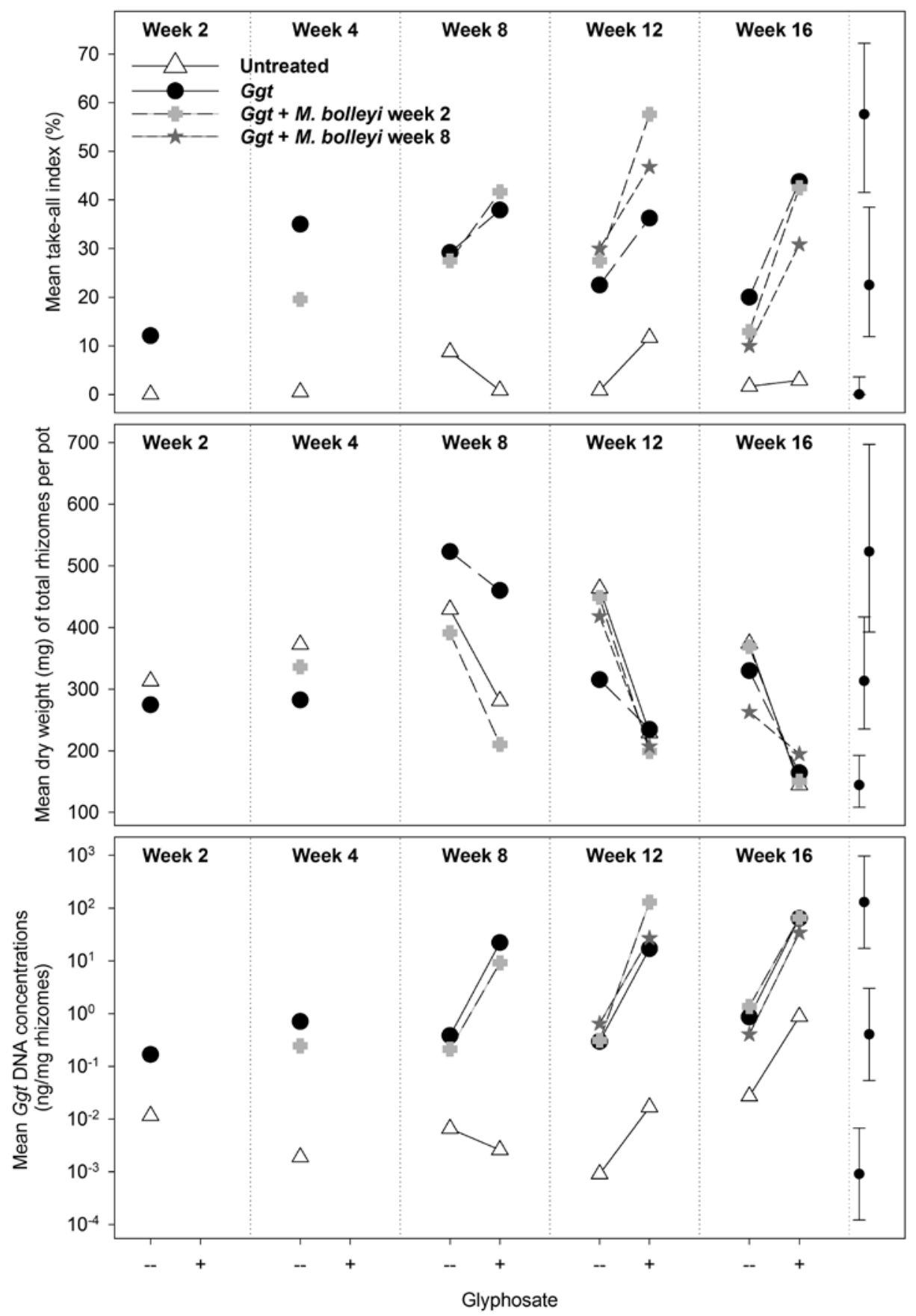

Figure 1 Mean take all indices, rhizome dry weights and Ggt DNA concentrations for rhizomes of Elytrigia repens plants with or without glyphosate treatment, added Ggt and Microdochium bolleyi over 16 weeks. Error bars are 95\% confidence limits for the largest, smallest and a mid-range mean within the plot. 
Table 2 Mean dry root weight from couch rhizomes and wheat seedlings grown for 7 weeks in sand with none or plus combinations of couch, glyphosate (glyph), Gaeumannomyces graminis var. tritici (Ggt) and Pseudomonas fluorescens PF1208-4 (95\% confidence limits).

\begin{tabular}{lcccc}
\hline Treatment & \multicolumn{2}{c}{ Couch $(\mathrm{g})$} & \multicolumn{2}{c}{ Wheat $(\mathrm{mg})$} \\
& Water & P. fluorescens & Water & P. fluorescens \\
\hline Wheat & - & - & $121.6_{(66.1,223.6)}$ & $136.7_{(74.3,251.4)}$ \\
Couch & $10.5_{(7.0,16.0)}$ & $12.7_{(8.4,19.3)}$ & - & - \\
GlyphCouch & $0.5_{(0.3,0.7)}$ & $0.3_{(0.2,0.5)}$ & - & - \\
Wheat+Couch & $10.8_{(7.2,16.4)}$ & $10.2_{(6.8,15.5)}$ & $42.5_{(23.1,78.1)}$ & $25.4(13.8,46.6)$ \\
Wheat+GlyphCouch & $0.3_{(0.2,0.5)}$ & $0.33_{(0.2,0.5)}$ & $96.0_{(52.2,176.5)}$ & $100.6_{(54.7,185.0)}$ \\
CouchGgt & $10.7_{(7.1,16.3)}$ & $10.8_{(7.1,16.3)}$ & - & - \\
GlyphCouchGgt & $0.2_{(0.1,0.3)}$ & $0.3_{(0.2,0.5)}$ & - & - \\
Wheat+CouchGgt & $9.4_{(6.2,14.2)}$ & $9.1_{(6.0,13.8)}$ & $25.2_{(13.7,46.4)}$ & $20.8_{(11.3,38.3)}$ \\
Wheat+GlyphCouchGgt & $0.2_{(0.1,0.2)}$ & $0.2_{(0.1,0.3)}$ & $67.5_{(36.7,124.1)}$ & $63.0(34.3,115.9)$ \\
\hline
\end{tabular}

contained an average of $2.8_{(1.5,5.0)}$ wheat plants per pot, with no significant difference between the treatments $(\mathrm{P}>0.4)$. The dry weights of roots of wheat plants grown in the presence of untreated couch was $40 \%$ less than when grown alone or with couch treated with glyphosate $(\mathrm{P}<0.001$, Table 1). Wheat root dry weight was a third lower in pots containing couch inoculated with $G g t$ than in healthy couch $(\mathrm{P}=0.015)$. The addition of $P$. fluorescens to the pots had no effect on dry weights of couch rhizomes $(\mathrm{P}>0.2)$ or wheat roots $(\mathrm{P}>0.4)$.

\section{Wheat take-all}

Take-all severity in roots of wheat plants grown together with Ggt-infected couch treated with glyphosate was highly variable and not significantly lower than that when grown with Ggt-infected untreated couch. Without Pseudomonas, take-all percent decreased from $37_{(11,73)}$ to $12_{(1,57)}$ with glyphosate, but with the bacterium increased from $36_{(11,72)}$ to $48_{(17,80) \text {. }}$ However, the addition of $P$. fluorescens also had no significant effect and the interaction of these treatments was not significant either $(\mathrm{P}>0.2)$.

\section{Ggt DNA}

Ggt DNA was not detected in tissue from pots without the Ggttreatment. None of the treatments significantly affected the concentration of Ggt DNA in couch rhizomes $(\mathrm{P}>0.4)$, which averaged $11.5_{(11.1,12.0)} \mathrm{ng} / \mathrm{mg}$ dry weight. Nor in wheat roots $(\mathrm{P}>0.5)$, although the Ggt DNA concentration increased in both the untreated- and glyphosatetreated wheat roots on average from 20.9(19.4, 22.5) to $59.6(56.0,63.4) \mathrm{mg} / \mathrm{mg}$ dry weight with the addition of $P$. fluorescens.

Because of the large differences in root mass between glyphosate-treated and non-treated couch plants, the quantity of Ggt DNA per nonglyphosate couch plants was 74 times more in those treated with glyphosate $(\mathrm{P}<0.001)$ (Table 3$)$. For wheat, the quantity of Ggt DNA per plant roots tended to be greater in plants grown with glyphosate-treated couch than with untreated couch $(\mathrm{P}=0.098)$. 
Table 3 Mean quantity of Ggt DNA in roots of wheat plants grown for 7 weeks in sand containing couch rhizomes infected with Gaeumannomyces graminis var. tritici (Ggt) and treated with or without glyphosate and Pseudomonas fluorescens (95\% Confidence Limits).

\begin{tabular}{lcccc}
\hline Treatment & \multicolumn{2}{c}{$\begin{array}{c}\text { Couch rhizomes } \\
(\mu \mathrm{g} / \text { rhizome dry weight })\end{array}$} & \multicolumn{2}{c}{$\begin{array}{c}\text { Wheat roots } \\
(\mathrm{ng} / \text { root dry weight })\end{array}$} \\
\cline { 2 - 5 } & \multicolumn{1}{c}{ Water } & Pseudomonas & Water & Pseudomonas \\
\hline CouchGgt & $181.2_{(31.6,1037.5)}$ & $108.9_{(19.0,623.9)}$ & - & - \\
GlyphCouchGgt & $2.2_{(0.4,12.6)}$ & $1.9_{(0.3,10.6)}$ & - & - \\
Wheat+CouchGgt & $58.6_{(10.2,336.8)}$ & $243.9_{(42.6,1395.7)}$ & $0.66_{(0.1,4.6)}$ & $1.4_{(0.2,11.7)}$ \\
Wheat+GlyphCouchGgt & $1.6_{(0.3,9.3)}$ & $2.2_{(0.4,12.4)}$ & $2.5_{(0.3,20.4)}$ & $6.8_{(0.8,55.3)}$ \\
\hline
\end{tabular}

The correlation (Pearson's $r$ ) between take-all and $\log _{10}$ Ggt DNA concentrations in wheat roots $(r=0.46)$ and couch rhizomes $(\mathrm{r}=0.47)$ were weak.

\section{DISCUSSION}

Usually, the risk of take-all in wheat increases by controlling Ggt-infected weeds with glyphosate (Baley et al. 2009; Bithell et al. 2009). In Experiment 1, glyphosate hastened decomposition of couch rhizomes and increased Ggt inoculum concentrationsinthedyingrhizomes. Thus,spraying couch with glyphosate is likely to exacerbate takeall in subsequent wheat crops in agreement with previous findings. Addition of $M$. bolleyi at either week 2 or 8 did not affect Ggt inoculum increase, but further growth of Ggt-infected rhizomes was reduced slightly indicating weak pathogenicity of M. bolleyi and its potential in enhancing rhizome decay after glyphosate application. As M. bolleyi is typically endophytic in grasses (Mandyam et al. 2010), greater effects in association with glyphosate may have been observed in couch had more time been allowed for colonisation within the rhizomes before harvest.

In Experiment 2, however, take-all severity in wheat tended to decrease when associated with glyphosate-treated couch. It only tentatively increased when P. fluorescens PF1208-4 was added. This increase was accompanied by an apparent increase in the concentration of Ggt DNA in the wheat roots associated the added $P$. fluorescens regardless of glyphosate treatment. This association suggests a possible synergistic relation between the two micro-organisms, which could be explored further. It was subsequently discovered by Warren et al. (2016) that the PF1208-4 isolate of $P$. fluorescens produced siderophores only, and not hydrogen cyanide produced by other $P$. fluorescens isolates collected from roots of second-year wheat in New Zealand. Also, the PF1208-4 isolate does not contain the PhlD gene, which codes for production of the antibiotic 2,4-diacetylphloroglucinol effective in suppressing take-all in some countries (Weller et al. 2007). Pseudomonas fluorescens isolates having these properties could have produced stronger effects against Ggt after glyphosate treatment couch.

The differences in the methods of applying the glyphosate may have contributed to the Ggt inoculum fluctuation in the experiments. In Experiment 1, the couch foliage was sprayed with glyphosate. In Experiment 2 the foliage was wiped to prevent chemical residues in the sand that would have affected growth of the wheat seedlings in the same pots. The dose of glyphosate per couch plant under spraying would most likely be lower than that under wiping, as in agreement with that observed. Take-all symptoms in the senescent rhizomes were expressed under spraying but masked by the blackened rhizomes under wiping. The slowly senescing rhizomes under spraying could have been more conducive to Ggt colonisation than the rapidly senescing rhizomes under wiping. This was reflected in the Ggt concentration. It increased in rhizomes of 
glyphosate-sprayed couch by 100 fold (Figure 1) compared to untreated couch, whereas in glyphosate-wiped couch it remained at about 11 ng Ggt DNA/mg dried rhizomes in both glyphosate-treated and untreated couch.

Results from this study suggest some soil microorganisms in fields with glyphosatesprayed weeds previously infected by Ggt may potentially play a role in contributing to severe take-all in subsequent wheat. We investigated the influence of only two selected micro organisms commonly associated with Ggt. However, whole microbial community structures could be implicated in suppression of Ggt in New Zealand soils (Chng et al. 2015) and hence affecting the interaction between Ggt and glyphosate. The influence of soil microorganism diversity, such as comparing natural and sterilised soil, and the influence of P. fluorescens strains on Ggt infection with glyphosate, should be investigated further.

\section{ACKNOWLEDGEMENTS}

Rob Craigie of the Foundation for Arable Research for comments on current farming practice. Plant \& Food Research staff Stan Ebdon for trial preparation, and Andy Pitman, Stephen Hoyte and John Fletcher for preparation of this manuscript. Funding was provided by the Ministry of Business Investment and Employment Project LINX 0804, Milestone 2.3.7.

\section{REFERENCES}

Bailey DJ, Gilligan CA 1999. Dynamics of primary and secondary infection in take-all epidemics. Phytopathology 89: 84-91.

Baley GJ, Campbell KG, Yenish J, Kidwell KK, Paulitz TC 2009. Influence of glyphosate, crop volunteer and root pathogens on glyphosate-resistant wheat under controlled environmental conditions. Pest Management Science 65: 288-299.

Bithell SL, Butler RC, Mckay A, Cromey MG 2009. Effect of glyphosate application to grass weeds on levels of 'Gaeumannomyces graminis' var. 'tritici' inoculum [online]. Plant Protection Quarterly 24: 161-167.
Chng S, Cromey MG, Dodd SL, Stewart A, Butler RC, Jaspers MV 2015. Take-all decline in New Zealand wheat soils and the microorganisms associated with the potential mechanisms of disease suppression. Plant and Soil 397: 239-259.

Chng SF, Cromey MG, Butler RC 2004. Mycoflora of rhizomes and roots of Elytrigia repens, a potential inoculum source for take-all in wheat. New Zealand Plant Protection 57: 59-66.

Chng SF, Cromey MG, Butler RC 2005. Evaluation of the susceptibility of various grass species to Gaeumannomyces graminis var. tritici. New Zealand Plant Protection 58: 261-267.

Gutteridge RJ, Zhang JP, Jenkyn JF, Bateman GL 2005. Survival and multiplication of Gaeumannomyces graminis var. tritici (the wheat take-all fungus) and related fungi on different wild and cultivated grasses. Applied Soil Ecology 29: 143-154.

Hammerschmidt R 1999. Phytoalexins: What have we learned after 60 years? Annual Review of Phytopathology 37: 285-306.

Hornby D 1981. Inoculum. In: Asher MJC, Shipton PJ eds. Biology and Control of Takeall. Academic Press, London. Pp. 271-293.

Hornby D, Beale R 2000. Take-all Management Guide. In., Monsanto Plc, Agricultural Sector, Maris Lane, Trumpington, Cambridge, UK. Pp. 39.

Hornby D, Bateman GL, Gutteridge RJ, Ward E, Yarham D 1998a. Take-all disease of cereals: a regional perspective. $\mathrm{CAB}$ International, UK. $384 \mathrm{p}$.

Hornby D, Bateman GL, Gutteridge RJ, Lucas P, Osbourn AE, Ward E, Yarham DJ 1998b. Takeall and cereal production systems. In: Takeall Disease of Cereals. CAB International, Cambridge, UK. Pp. 103-164

Jadubansa P, Lethbridge G, Bushell ME 1994. Physiology of production of viable biomass and spore inoculum for the biocontrol agent Idriella (Microdochium) bolleyi. Enzyme and Microbial Technology 16: 24-28. 
Keenan S, Cromey MG, Harrow SA, Bithell SL, Butler RC, Beard SS, Pitman AR 2015. Quantitative PCR to detect Gaeumannomyces graminis var. tritici in symptomatic and nonsymptomatic wheat roots. Australasian Plant Pathology 44: 591-597.

Kirk JJ, Deacon JW 1987. Control of the takeall fungus by Microdochium bolleyi, and interactions involving Microdochium bolleyi, Phialophora graminicola and Periconia macrospinosa on cereal roots. Plant and Soil 98: 231-237.

Kwak YS, Weller DM 2013. Take-all of Wheat and Natural Disease Suppression: A Review. Plant Pathology Journal 29: 125-135.

Lee Y, Nelder JA, Pawitan Y 2006. Generalized Linear Models with Random Effects: Unified Analysis via H-likelihood: Monographs on Statistics and Applied Probability, v.106. Chapman \& Hall/CRC Press, London. 416 p.

Mandyam K, Loughin T, Jumpponen A 2010. Isolation and morphological and metabolic characterization of common endophytes in annually burned tallgrass prairie. Mycologia 102: 813-821.

McCullagh P, Nelder JA 1989. Generalized Linear Models. Chapman \& Hall, London. 511 +xix p.
Mekwatanakarn P, Sivasithamparam K 1987. Effect of certain herbicides on growth and pathogenicity of take-all fungus on wheat (Triticum aestivum L). Biology and Fertility of Soils 5: 31-35.

Payne R, Murray D, Harding S 2015. The Guide to the Genstat ${ }^{\circledR}$ Command Language (Release 18). VSN International, Hemel Hempsted, Hertfordshire, UK.

Steinrucken HC, Amrhein N 1980. The herbicide glyphosate is a potent inhibitor of 5-enolpyruvyl-shikimic-acid 3-phosphate synthase. Biochemical and Biophysical Research Communications 94: 1207-1212.

VSN International Ltd 2013. CycDesigN 5.1 A package for the computer generation of experimental designs. VSN International Ltd, Hertfordshire, England.

Warren RM, Chng SF, Butler RC 2016. Functional characteristics of New Zealand wheat rhizosphere Pseudomonas fluorescens isolates and their potential to inhibit in-vitro growth of Gaeumannomyces graminis var. tritici. New Zealand Plant Protection 69: 48-56.

Weller DM, Landa BB, Mavrodi OV, Schroeder KL, De La Fuente L, Bankhead SB, Molar RA, Bonsall RF, Mavrodi DV, Thomashow LS 2007. Role of 2,4-diacetylphloroglucinolproducing fluorescent Pseudomonas spp. in the defense of plant roots. Plant Biology 9: 4-20. 